\title{
Refraction as a Measure of Soluble Carbohydrates in Storage Roots of Asparagus
}

\author{
Carmen Feller ${ }^{1}$ and Matthias Fink \\ Institute of Vegetable and Ornamental Crops, Modelling/Knowledge-Transfer, \\ Th.-Echtermeyer-Weg 1, Großbeeren, D-14979 Germany
}

Additional index words. Asparagus officinalis, soluble solids concentration

\begin{abstract}
The objective of our study was to determine how accurately refractometry can quantify soluble carbohydrates in the storage roots of asparagus (Asparagus officinalis L.). Fructose, glucose, sucrose, and fructans as well as refraction were measured in 51 root samples that were taken from commercial fields. There was substantial variation in refraction both within roots of the same plant $(\mathrm{cv}, 6 \%)$ and within plants in the same field (cv, 20\%). Samples of asparagus root sap contained fructose, glucose, sucrose, and fructans in varying fractions and, in addition, significant amounts of other solubles, which contributed considerably to refraction. Therefore, refraction readings are no direct measure of fructose, glucose, sucrose, and fructans in asparagus root sap. However, the concentration of these carbohydrates can be well estimated by a regression function, which uses refraction readings as input $(r=0.89)$.
\end{abstract}

The measurement of soluble solids by refractometry is a widely used method to determine the quality of marketable plant parts. For instance, soluble solids concentration was used as a measure of sugar content in sugar cane (Mamet, 1999), sugar beet (Campbell, 2002), muskmelon (Beaulieu et al., 2003), tomato (Stommel et al., 2005), and table beet (Feller and Fink, 2004). In contrast to laboratory methods, refractometry measurements of soluble carbohydrates are both quick and inexpensive. Recently Wilson et al. (2002) and Drost (2005) suggested the use of a refractometer for measuring root soluble carbohydrates in asparagus. The authors stated that growth of spears and ferns during the crop's annual cycle is associated with a characteristic pattern of depletion and accumulation of soluble carbohydrates in storage roots. Detecting deviations from the normal pattern could help to diagnose crop problems, such as unwanted excessive depletion of carbohydrates incited by harvest periods that are too long. Frese and Dambroth (1987) noted that refraction readings from plant sap that contains different types of sugars must be interpreted with caution, because each sugar has a different refraction

\footnotetext{
Received for publication 30 Dec. 2005. Accepted for publication 30 Mar. 2006.

Financial support from the Ministries of Agriculture of the Federal Republic of Germany, and from the states of Brandenburg and Thuringen is gratefully acknowledged.

We thank Mrs. S. Starke and Mrs. G. Brandt for their skillful technical assistance.

${ }^{1}$ To whom reprint requests should be addressed; e-mail feller@igzev.de
}

index. The estimation of total sugar content would be especially error prone if both sugar distribution of samples is not constant and the sugars differ strongly in their specific refractive index increment (SRI), which describes how much the refractive index of a solution changes with respect to the concentration of the solute.

It is not known whether the composition of and variability in storage carbohydrates of asparagus roots permits accurate assessment with a refractometer. The objective of our study was to determine how accurately soluble carbohydrates in storage roots of asparagus can be assessed using refractometry.

\section{Materials and Methods}

Plant samples were taken near Vetschau, Germany, from two commercial fields where asparagus cultivar Gijnlim had been planted in 1995 (field 1) and in 1999 (field 2). Standard commercial field management for white asparagus was practiced. Between Oct. 2002 and Oct. 2004, 4 and 10 samples were taken from field 1 and field 2 respectively. On each sampling date, six plants were excavated. For this purpose, all soil was sampled down to $0.8 \mathrm{~m}$ from $0.4 \times 1.2-\mathrm{m}$ plots, each with one plant in the center of the plot. Then samples were randomly grouped into three replicates with two plants each. There is no evidence that carbohydrates are inhomogeneously distributed between storage root sections and, therefore, we did not consider it during subsampling. Hence, all parts of all storage roots with a diameter of more than $3 \mathrm{~mm}$ were collected from each replicate. All these roots were rinsed with tap water, cut, and mixed. Then three subsamples were taken from the mixed root sample.
The first subsample, $\approx 300 \mathrm{~g}$ fresh matter, was squeezed out, resulting in $10 \mathrm{~mL}$ root sap, which was stored in test tubes to avoid dehydration. Refraction of the sap was measured within 60 min after pressing with a digital refractometer (PR-101, Atago, Bellevue, WA). Measurements were repeated eight times [coefficient of variation (CV), 1.3\%] and an average was calculated for each sample.

Dry matter content of root sap was determined by drying sap samples in Petri dishes for $1 \mathrm{~d}$ at $70{ }^{\circ} \mathrm{C}$ in a ventilated drying chamber.

The second subsample, $\approx 60 \mathrm{~g}$ fresh matter, was lyophilized and milled. Before analysis, samples were heated to $80{ }^{\circ} \mathrm{C}$ for $30 \mathrm{~min}$ to denature enzymes. Then the carbohydrates were analyzed in a four-step process: 1) glucose and fructose were determined enzymatically using a test kit of Roche Diagnostics, Mannheim, Germany; 2) sucrose was hydrolyzed with $\alpha$-glycosidase, then sucrose content was determined by the difference of fructose before and after hydrolyzation of saccharose; 3 ) fructans were hydrolyzed with fructanase, then glucose and fructose were determined enzymatically using a test kit of Roche Diagnostics; and 4) fructan content was determined by the difference of glucose and fructose before and after hydrolysis of fructans. The method for analyzing fructans is described in detail by Koball and Habel (2002).

The third subsample, $\approx 500 \mathrm{~g}$ fresh matter, was dried for $7 \mathrm{~d}$ at $70{ }^{\circ} \mathrm{C}$ in a ventilated drying chamber to obtain dry matter content.

SRI, expressed as refraction $\left({ }^{\circ} \mathrm{Brix}\right)$, of fructose, glucose, sucrose, and fructans was determined with the PR-101 digital refractometer. Pure glucose and sucrose (Merck, Darmstadt, Germany), fructose (Roth $\mathrm{GmbH}$ \& Co, Karlsruhe, Germany), and fructans (Sigma-Aldrich Chemie GmbH, Munich, Germany) were dissolved in distilled water at three concentrations to obtain a calibration line. SRI of each substance was estimated from the slope of the calibration line. Because fructans from asparagus were not available, fructans from dahlia tubers and chicory root were used.

\section{Results and Discussion}

According to Pressman et al. (1993) storage roots of asparagus accumulate primarily fructans and smaller amounts of sucrose, glucose, and fructose. Woolley and Woolley (2002) confirmed that fructans are the predominant storage carbohydrates in asparagus, and they noted that reports on average chain length of fructans vary (Martin and Hartmann, 1990; Pressman et al., 1993; Shelton and Lacy, 1980; Shiomi, 1993). Martin (1989) reported small amounts of starch in all organs of asparagus; however, Pressman et al. (1989) did not detect starch in either the shoot or the root. Based on this previous work, fructose, glucose, sucrose, and fructans may be considered the most important compounds in the assessment of storage carbohydrates of asparagus and thus 
were selected for analysis in this experiment. The sum of these substances is subsequently referred to as $f s+g l+s u+f t$.

In both fields, $f s+g l+s u+f t$ decreased during spear harvest and fern development (day 90 to day 200; Fig. 1) and increased during summer after canopy establishment (day 201 to day 300; Fig. 1). This confirms the characteristic pattern of seasonal changes in carbohydrate content of asparagus as reported and analyzed in previous work (Haynes, 1987; Pressman et al., 1993; Robb, 1984; Shelton and Lacy, 1980; Wilson et al., 2002). In the context of our study, the knowledge of this pattern was useful to schedule plant samples to compile a data set with a broad range in $f_{s}+g l+s u+f t$, refraction, and dry matter content.

The sugar distribution in our data varied considerably. Fraction of fructans was $\approx 50 \%$ of $f s+g l+s u+f t$ in samples with low $f s+g l+$ $s u+f t$ and increased up to $85 \%$ with increasing $f s+g l+s u+f t$ (Fig. 2). Fractions of fructose, glucose, and sucrose were in the range of $1 \%$ to $37 \%, 1 \%$ to $5 \%$, and $6 \%$ to $54 \%$ respectively.

Although the SRI of asparagus fructans has not been reported in the literature, our measurements showed that the SRI of dahlia fructans and chicory fructans $(0.41$ and 0.32 ${ }^{\circ}$ Brix $\cdot 100 \mathrm{~g} \cdot \mathrm{g}^{-1}$ respectively) were considerably lower than the SRIs of fructose, glucose, and sucrose $\left(1.00,1.04\right.$, and $0.99{ }^{\circ}$ Brix $\cdot 100$ $\mathrm{g} \cdot \mathrm{g}^{-1}$ respectively; Fig. 3 ).

Because there was no pure asparagus fructans available for purchase, we considered fructans from other plant species as examples to illustrate the effect of different SRIs when carbohydrates are estimated from Brix readings. Taking the average of $\mathrm{SRI}_{\text {dahlia fructans }}$ and $\mathrm{SRI}_{\text {chicory fructans as an }}$ estimate for $\mathrm{SRI}_{\text {asparagus fructans }}$, the potential error of determining $f s+g l+s u+f t$ based on refraction readings was assessed by calculating an average $\mathrm{SRI}_{\text {sample }}$ for each sample separately:

$$
\begin{aligned}
\mathrm{SRI}_{\text {sample }}= & \mathrm{SRI}_{\text {fructose }} \times \mathrm{F}_{\text {fructose }} \\
& +\mathrm{SRI}_{\text {glucose }} \times \mathrm{F}_{\text {glucose }} \\
& +\mathrm{SRI}_{\text {surcose }} \times \mathrm{F}_{\text {sucrose }} \\
& +\mathrm{SRI}_{\text {fructans }} \times \mathrm{F}_{\text {fructans }}
\end{aligned}
$$

where $\mathrm{SRI}_{\text {substance }}$ is the specific refraction index increment of a substance $\left({ }^{\circ}\right.$ Brix $\cdot g_{\text {substance }}{ }^{-1} \cdot 100 \mathrm{~g}_{\text {solution }}$ ) and $\mathrm{F}_{\text {substance }}$ is the fraction of total measured carbohydrates (measured in gram of substance per gram of $f r+s r+g l+f t)$.

The $\mathrm{SRI}_{\text {average }}$ calculated for each sample varied from 0.42 to $0.82^{\circ} \mathrm{Brix} \cdot \mathrm{g}^{-1} \cdot 100 \mathrm{~g}$. This demonstrates that assuming a constant $\mathrm{SRI}_{\text {average }}$ in samples with varying sugar distribution can cause a substantial error in estimating $f s+g l+s u+f t$ of asparagus roots.

The expected refraction can be calculated from known solute concentration and SRI for each component (Wyatt Technology, 2005):

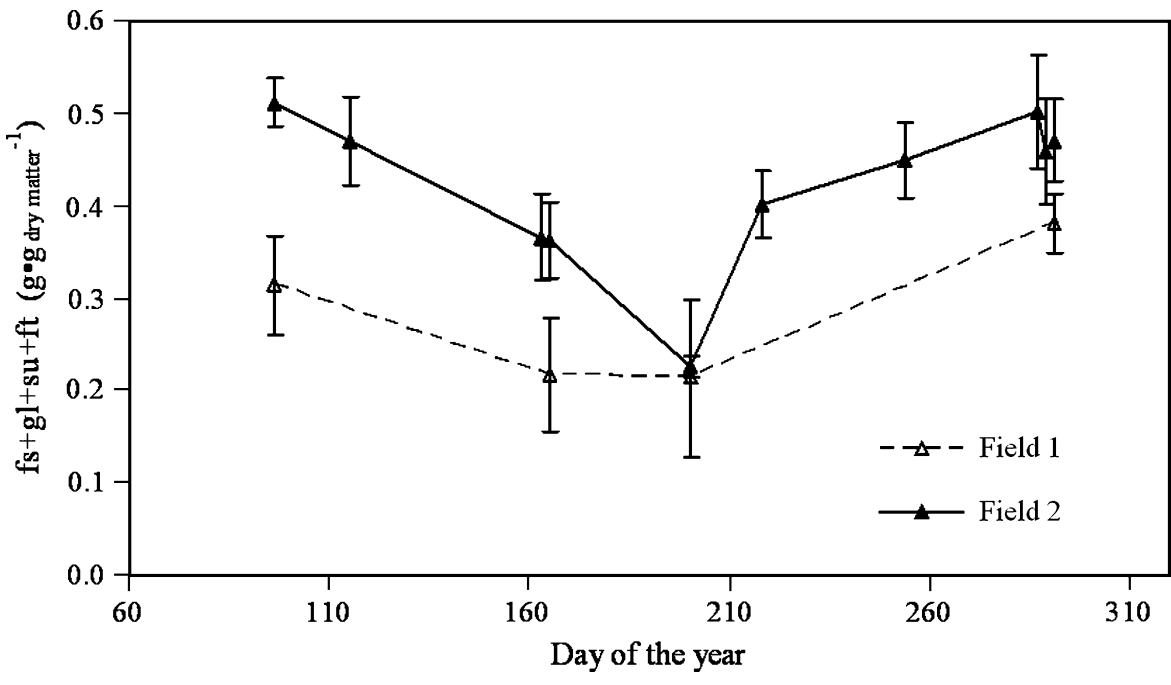

Fig. 1. Sum of fructose, glucose, sucrose, and fructans $(f s+g l+s u+f t)$ in asparagus roots related to time. Dots denote averages of three samples. Error bars show SD.

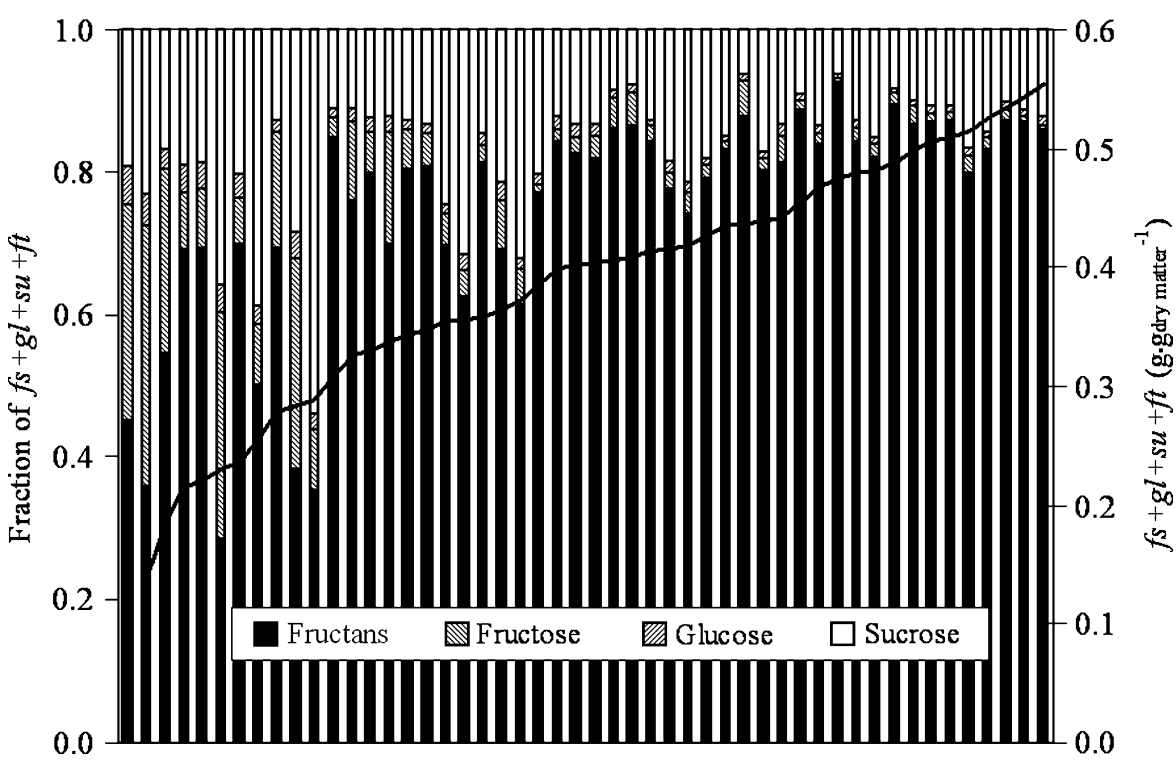

Fig. 2. Fractions of fructose $(f s)$, glucose $(g l)$, sucrose $(s u)$, and fructans $(f t)$ in asparagus roots. Each bar shows one sample. Bars are ordered by ascending content of $f_{s}+g l+s u+f t$. Line shows $f s+g l+s u+f t$.

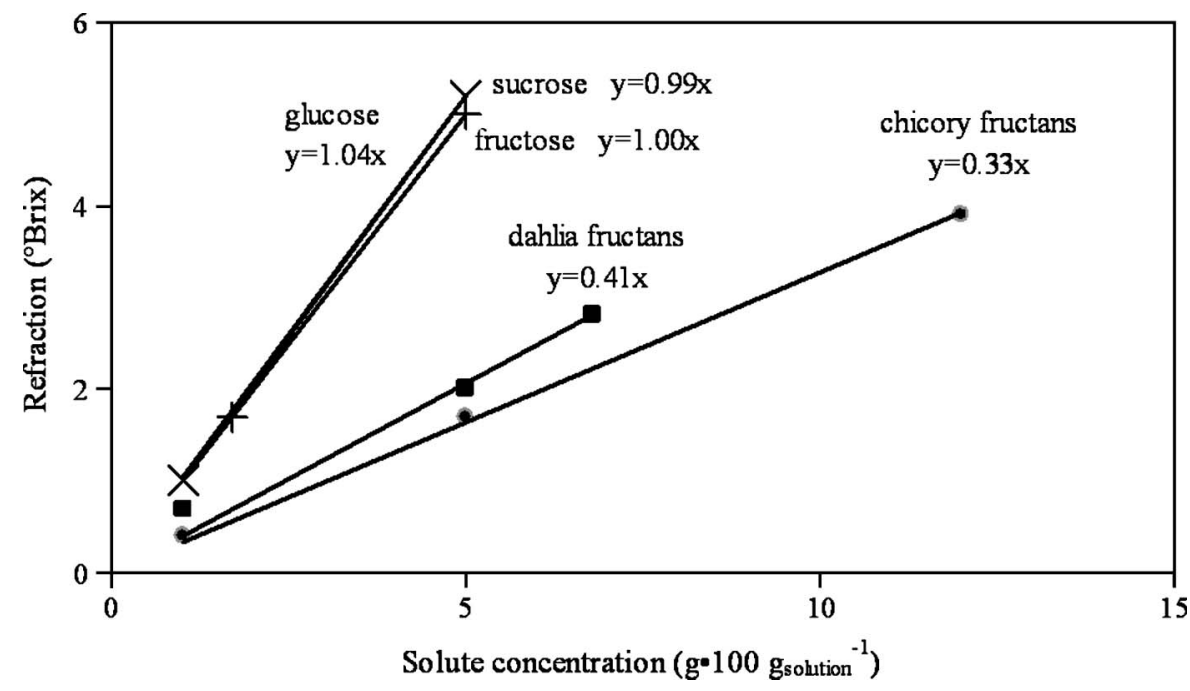

Fig. 3. Refraction of pure fructose, glucose, sucrose, and refraction of dahlia fructans and chicory fructans related to solute concentration. Lines are regression lines. Lines for fructose and sucrose are on top of each other. 


$$
\begin{aligned}
& \text { Calculated refraction }=S \mathrm{SI}_{\text {fructose }} \\
& \times \mathrm{C}_{\text {fructose }}+\mathrm{SRI}_{\text {glucose }} \times \mathrm{C}_{\text {glucose }} \\
& +\mathrm{SRI}_{\text {sucrose }} \times \mathrm{C}_{\text {sucrose }}+\mathrm{SRI}_{\text {fructans }} \\
& \times \mathrm{C}_{\text {fructans }}
\end{aligned}
$$

where $\mathrm{SRI}_{\text {substance }}$ is the specific refraction index increment of a substance (measured in degrees Brix per gram of substance per $100 \mathrm{~g}$ solution) and $\mathrm{C}_{\text {substance }}$ is the concentration of substance (measured in gram of substance per $100 \mathrm{~g}$ solution).

Calculated refraction (Eq. 2) and measured refraction were significantly correlated (Fig. 4). However, regression analysis revealed that the axis intercept differed significantly from zero $(P<0.001)$ and the slope differed significantly from one $(P<0.001)$. Because measured refraction was, on average, five times higher than calculated refraction (Fig. 4), we concluded that asparagus root sap contained significant amounts of solubles in addition to the fructose, glucose, sucrose, and fructans $\left(f_{S}+g l+\right.$ $s u+f t)$ measured in our study. This result is supported by measurements of dry matter of sap, which showed that an increase of soluble dry matter was explained only partly by an increase in $f s+g l+s u+f t$ (Fig. 5).

As reported for many other crops, refraction was closely correlated to total soluble content also in asparagus root sap (Fig. 6). Because total soluble content was correlated to $f s+g l+s u+f t$ (Fig. 5), there was also a close correlation between refraction and $f s+g l+s u+f t(r=0.89$, Fig. 7). Wilson et al. (2002) reported a similar correlation coefficient $(r=0.91 ; \mathrm{n}, \approx 400)$, which was determined in a survey of asparagus crops used for green spear production.

As reported by Wilson et al., (2002) there was a substantial variation in soluble solids concentration within plants. Our data showed a cv of $6 \%$ and $20 \%$ within roots of the same plant and within plants in the same field, respectively. Applying the recommended sample size of 20 (Wilson et al., 2002) to our data resulted in a narrow confidence interval for estimated $f s+g l+s u+f t$ (Fig. 7).

In summary it is noted that samples of asparagus root sap contained fructose, glucose, sucrose, and fructans in varying fractions and, in addition, significant amounts of other solubles, which contributed considerably to refraction (Fig. 4). Therefore, $f_{S}+g l+$ $s u+f t$ cannot be determined directly from refraction readings, but must be estimated by a regression function, which uses refraction readings as input. This method worked well in our study with two fields used for white asparagus production (Fig. 7, $r=0.89$ ). The two fields differed in planting date, hence in crop history and carbohydrate content (Fig. 1). The relation between refraction and $f s+g l+$ $s u+f t$ was not significantly different between fields (regression analysis not shown). Our results agree with previous work of Wilson (2005), who showed that sampling site had little effect on the relation between carbohydrate content of asparagus roots and refraction.

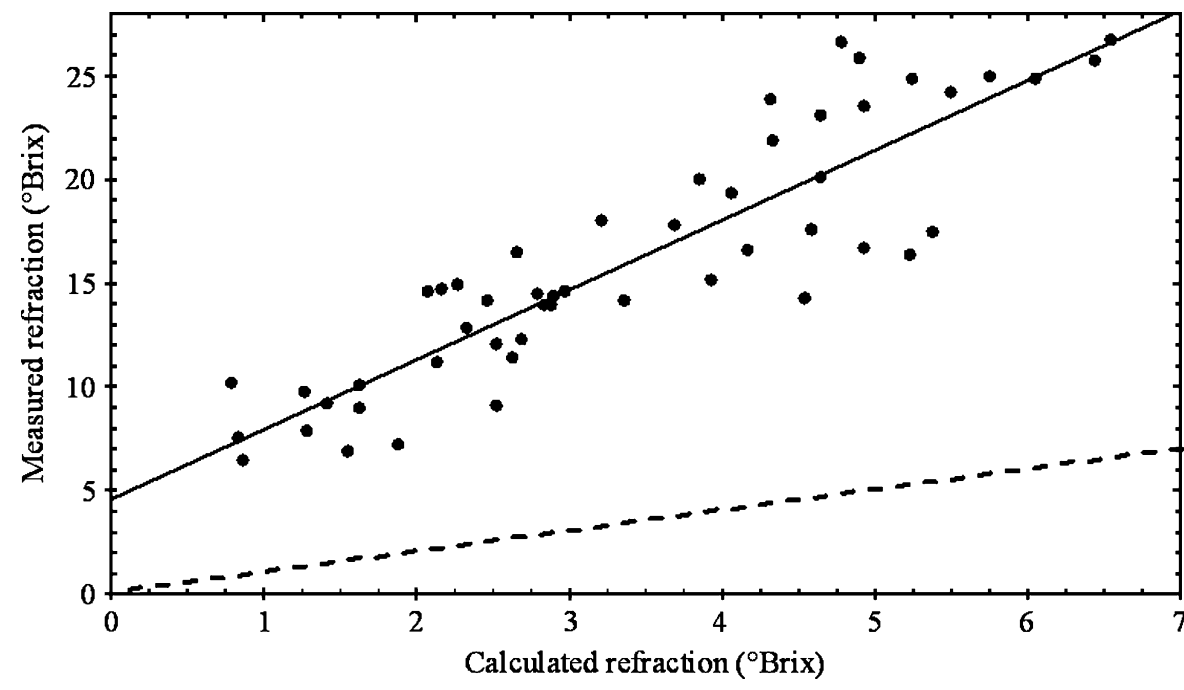

Fig. 4. Measured refraction related to refraction calculated with Eq. 2. Solid line is the regression line $(y=$ $4.57+3.36 \mathrm{x} ; r=0.89)$. Dashed line is the 1:1 line.

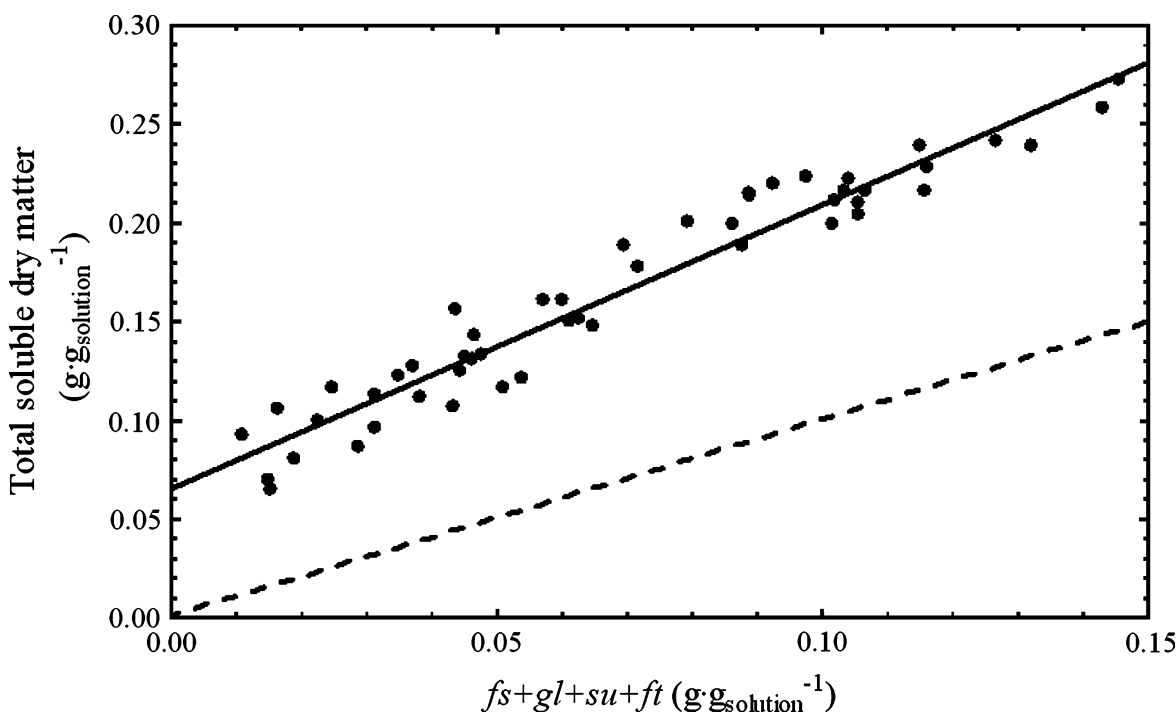

Fig. 5. Total soluble dry matter related to sum of fructose, glucose, sucrose, and fructans $(f s+g l+s u+f t)$ Solid line is the regression line $(\mathrm{y}=0.0654+1.54 \mathrm{x} ; r=0.97)$. Dashed line is the $1: 1$ line.

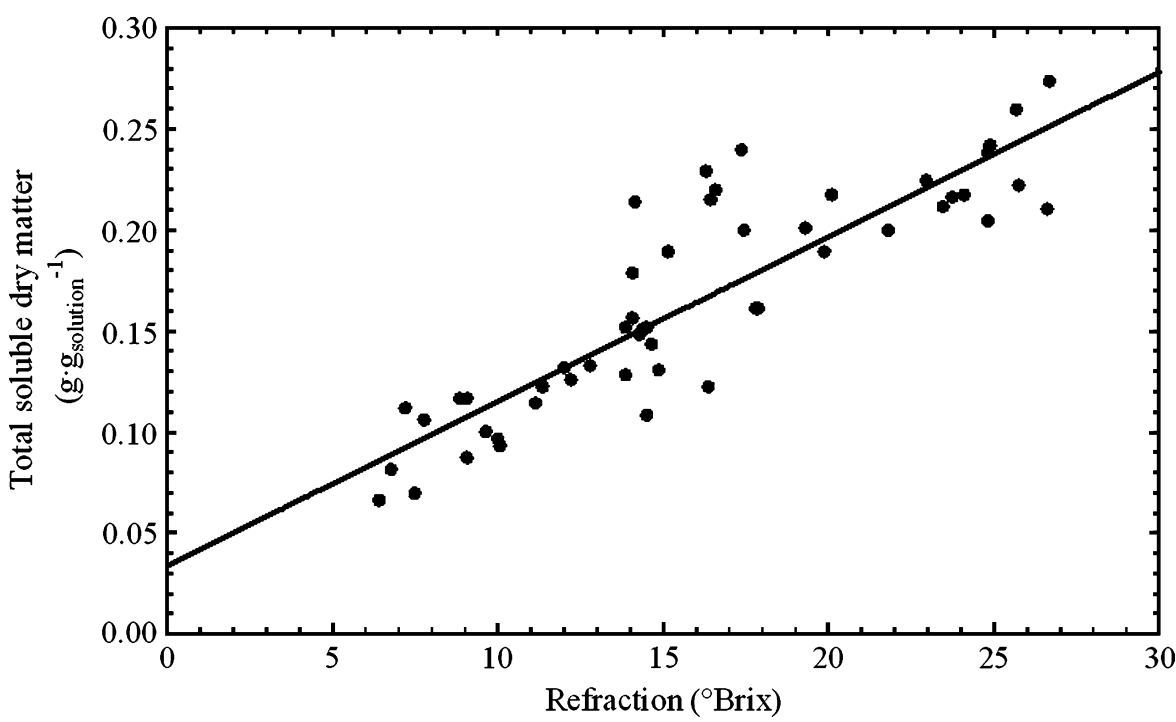

Fig. 6. Total soluble dry matter related to refraction. Dots denote measurements. Line is the regression line $(\mathrm{y}=0.0337+0.00815 \mathrm{x} ; r=0.88)$. 


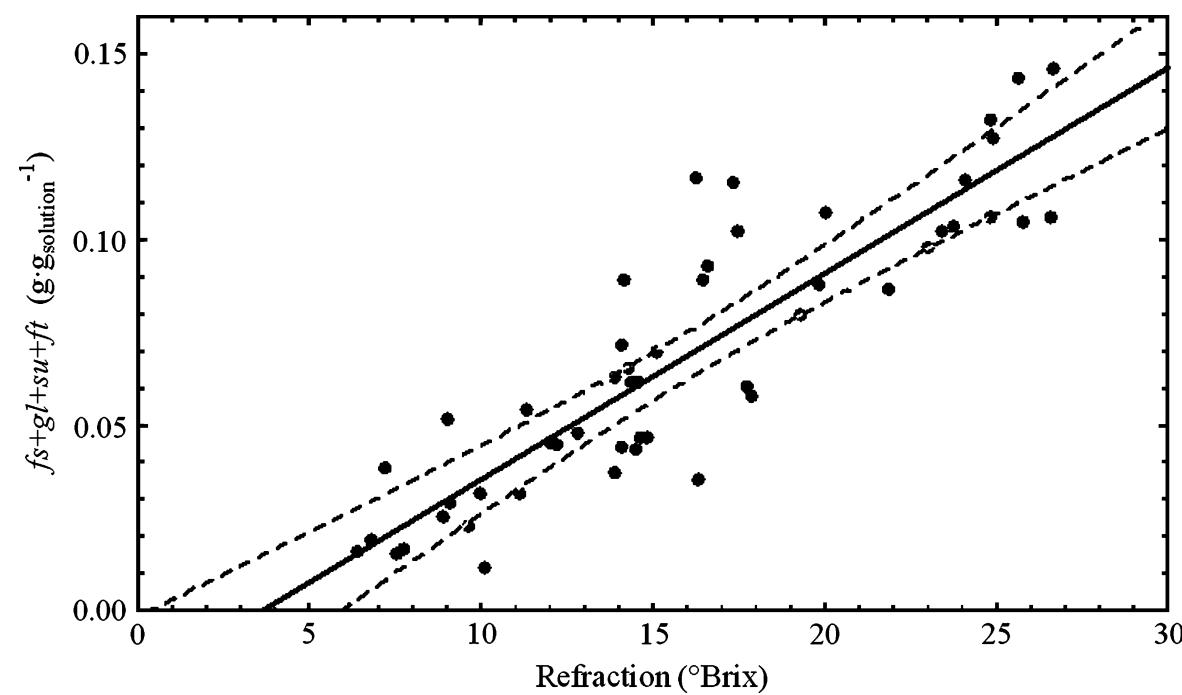

Fig. 7. Sum of fructose, glucose, sucrose, and fructans $(f s+g l+s u+f t)$ related to refraction. Dots denote measurements. Straight line is the regression line $(\mathrm{y}=-0.0201+0.00554 \mathrm{x} ; r=0.89)$. Curves show confidence interval for a sample size of $20(P<0.05)$.

\section{Literature Cited}

Beaulieu, J.C., J.M. Lea, G. Eggleston, and Z. Peralta-Inga. 2003. Sugar and organic acid variations in commercial cantaloupes and their inbred parents. J. Amer. Soc. Hort. Sci. 128:531-536.

Campbell, L.G. 2002. Sugar beet quality improvement. J. Crop Prod. 5:395-413.

Drost, D. 2005. AspireUS is an interactive decision support system. 29 Nov. 2005. www. aspireus.com.

Feller, C. and M. Fink. 2004. Nitrate content, soluble solids content, and yield of table beet as affected by cultivar, sowing date and nitrogen supply. HortScience 39:1255-1259.
Frese, L. and M. Dambroth. 1987. Research on the genetic resources of inulin containing chicory (Cichorium intybus). Plant Breed. 99:308-317.

Haynes, R.J. 1987. Accumulation of dry matter and changes in storage carbohydrate and amino acid content in the 1 st 2 years of asparagus growth. Sci. Hort. 32:17-23.

Koball, G. and A. Habel. 2002. Vergleich verschiedener Methoden zur Inulinbestimmung in Getreidelebensmitteln. Getreide, Mehl Brot. 56:198-203.

Mamet, L.D. 1999. The reliability of refractometric field Brix measurement. Int. Sugar J. 101:464 468.

Martin, S. 1989. Untersuchungen über den Kohlehydratstoffwechsel von Spargel (Asparagus officinalis L.) in Abhängigkeit von der jahreszeitlichen Entwicklung der Pflanze. Fakultät III-Agrarwissenschaften I. Univ. Hohenheim, Germany. PhD Diss.

Martin, S. and H.D. Hartmann. 1990. The content and distribution of the carbohydrates in asparagus. Acta Hort. 271:443-444.

Pressman, E., A.A. Schaffer, D. Compton, and E. Zamski. 1989. The effect of low temperature and drought on the carbohydrate content of asparagus. J. Plant Physiol. 134:209-213.

Pressman, E., A. Schaffer, D. Compton, and E. Zamski. 1993. Seasonal changes in the carbohydrate content of two cultivars of asparagus. Sci. Hort. 53:149-155.

Robb, A.R. 1984. Physiology of asparagus (Asparagus officinalis) as related to the production of the crop. N. Z. J. Expt. Agr. 12:251-260.

Shelton, D.R. and M.L. Lacy. 1980. Effect of harvest duration on yield and on depletion of storage carbohydrates in asparagus roots. J. Amer. Soc. Hort. Sci. 105:332-335.

Shiomi, N. 1993. Structure of fructopolysaccharide (asparagosin) from roots of asparagus (Asparagus officinalis L.). New Phytol. 123:263-270.

Stommel, J., J.A. Abbott, R.A. Saftner, and M.J. Camp. 2005. Sensory and objective quality attributes of beta-carotene and lycopene-rich tomato fruit. J. Amer. Soc. Hort. Sci. 130: 649-653.

Wilson, D.R., C.G. Cloughley, and S.M. Sinton. 2002. ASPIRENZ: A decision support system for managing root carbohydrate in asparagus. Acta Hort. 589:51-58.

Wilson, D.R. 2005. Carbohydrates and yield physiology of asparagus a global overview. $12 \mathrm{Dec}$. 2005. www.ias2005.com/download/5-1. pdf2.

Woolley, K. and D.J. Woolley. 2002. Studies on remobilization of fructans from asparagus roots during harvest using carbon-14 and high performance liquid chromatography. Acta Hort. 589:273-279.

Wyatt Technology. 2005. Dn/dc with an Optilab. 29 Nov. 2005. http://www.wyatt.com. 